\title{
HUMAN AND ANIMAL \\ INTELLIGENCE: A QUESTION OF DEGREE AND RESPONSIBILITY
}

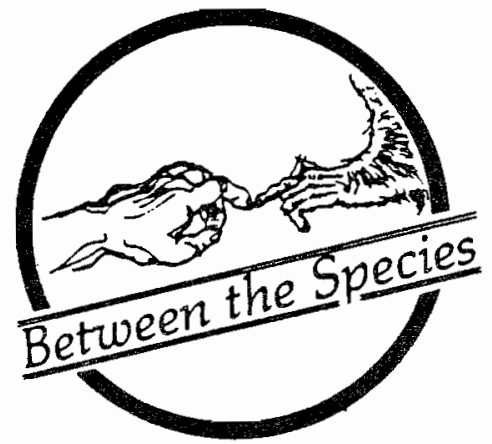

\author{
JOHN HUMMER \\ California State University, Hayward
}

When NASA launched its recent series of Voyager spacecraft on multi-year joumeys to the outer planets of our solar system, journeys that will take them beyond our solar system to destinations we know not where, the space agency included on each Voyager a capsule containing artifacts designed to commuicate with alien beings. The artifacts were designed first to explain our location in the Milky Way galaxy, our physiognomy, our cultural institutions and symbols, and certain rudiments of a possible mathematical language of communication. Presumably, any alien beings that might chance upon these spacecraft would be able to decipher the meaning of the contents, and if they are logical, benign, and intelligent beings, they will seek to communicate with us and relieve us of our sense of.isolation as possibly the only intelligent beings in the universe.

It is almost impossible to inagine what the tremendous impact on human history would be if we were to receive a return manuscript in a bottle, so to speak, or some other manifestation of an answer to our hopes and inquiries. Humans are not alone in the universe! There are other intelligent, sentient beings in the universe who could, perhaps, give us their wisdom and their perspective to break through the terrible and seemingly insoluble problems that we face. And perhaps best of all, we might find some way to return to the harmonious and natural state of living that eludes us in our much synthesized world.

But sane would ask why we must search the far reaches of the universe for a consciousness different from our own, when we live on a planet that presents us with a wonderful multiplicity of life, vibrant with species that we know virtually nothing about, and from whose intelligence and adaptive skills we could gratefully learn. We literally have "alien" life and a presentiment of consciousness right at our feet and all around us in every enviromment that humankind itself has come to live in, and sone that are as yet uninhabitable for us. Animal life from insects to higher mamnals abounds on our planet, though in nearly every respect it is threatened by human maladaptation to the enviromment and our lack of understanding of its fragile interrelationships.

Until recently there have been pitifully few attempts by humans to commicate with and "learn the wisdom of" our fellow beings on Farth. But is it possible for us to learn the "language" and the true capacities of other animals? Do animals have intelligence at all? The answers to these questions are vital to our ability to live on and manage this planet. And they are vital to us if we are ever really to understand our own capacities, as well.

\section{Evolution and Consciousness}

Long before Charles Darwin developed the scientific theory of biological evolution and twentieth century astrophysicists developed a theory for the evolution of planets, stars, and galaxies, the philosophers of India put forth a concept of evolution that remarkably parallels our modern scientific theories. Stories of creation and evolution found in the ancient Hindu scriptures, the Upanishads, some three thousand years old, tell of a kind of consciousness that pervades all of creation. This consciousness they called "At-

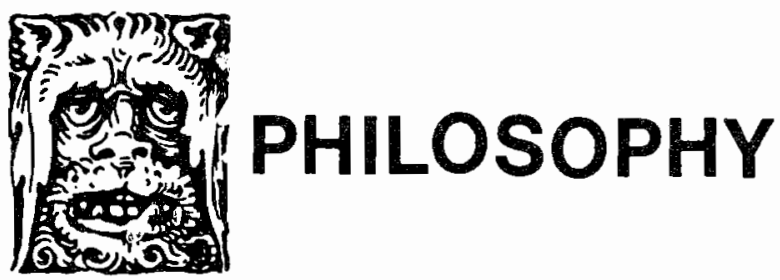


man," which, aware anly of itself, began with the most basic compounds, such as rocks and minerals, and through a process of successive complexity and combination of molecules, crossed the threshold from inorganic to organic matter. And again through a process of combination, complexity, and "karmic" experience (learning), which the Hindus called "reincarnation" ar rebirth after the perishing of the previous termoral form, consciousness moved up the ladder of creation from plant, to insect, to vertebrate, and through the phyla and classes of vertebrates, finally to arrive at the crowning achievement of creation-humanity. Humanity itself is continually in the process of refinement throuqh this same law of reincarnation. At each stage of this progression all that has been gathered from previous stages renains as a part of the newly complex being; nothing is lost; rather, each new stage accrues new material for its life process while keeping vestiges of the old.

When we consider the miracle of life-that is, that raw matter has become animate and sensate through the fifteen billion years of the universe's existence, that the whole of our existence has become so much more than the sum of our molecular parts-it is not hard to feel the profound awe that the ancients felt for creation. Looking about them and seeing the vast array of plant and animal life, each with its own niche and set of behaviors, and also seeing that humans possessed many of the traits of other animals, the ancients set down their metaphysical rule of evolution. We continue to this day to grapple with our understanding of all that came to pass. Most perplexing of all, at the center of this miracle of life lies its greatest achievenent, and, perhaps, its greatest prablem, as well--consciousness. What is it? How does it manifest itself? And for our purposes, do animals have it, and, if so, how is it different from our human consciousness?

To answer these questions, we must first come up with an operative definition of what consciousness is. The definition we use must have a satisfactory scientific and phenomenological foundation. The problem, of course, is that definitions have varied from one school to another, each defending its own narrowly selected criteria. Behaviorists deny that there is anything like consciousness per se. Rather, there are merely stimuli that elicit learned responses-- the reper- toire of responses having been passed on from generation to generation, changing only as envirommental needs dictate.

At the other extreme, philosophers who have followed on the path laid out by Descartes see the mind as something that is intangible, inaccessible, and, certainly, mysterious in its capabilities. All of the mind's activities are based on the axis of reality-thought itself. Taken to its extreme, external reality is not even a proven fact, and the organism is trapped within the walled city of the mind.

However, in the latter part of the twentieth century, most philosophers and scientists, including those who study artificial intelligence (the science of cybernetics), are willing to postulate the existence of scme form of "consciousness" and are not afraid to look for it in the study of animal and human behavior and the intricacies of neurophysiology, one thing they do agree on--the more complex the organism, the greater its capacity and diversity of mental states. That is, the complexity of mental experience and awareness seems to correlate directly with the complexity and structure of the brain which sits at the center of the body's neurological systen.

Most scientists would directly link an organism's "mental states" to the capacity of its brain, and the ratio of its brain size to body mass. Another yardstick for measuring awareness is behavior--how an organism's experiences and sensations are processed and channeled back into some form of activity. Even here, thexe may be seeming contradictions to the rule correlating brain complexi$t_{Y}$ with behavior when one compares the energetic social organization of ants and bees with the seeming indolence of a mammalian tree sloth. Their body structures are radically different: the insects have scarcely any brain at all, while the sloth, though a lower order manmal, has an incomparably more complex nervous system and brain. These widely different animals have, nevertheless, many activities in common; i.e., they interact with their respective enviroments, and they share qualities of locomotion, foraging, sexual reproduction, etc., with other animals. So, we must ask: What is the significance, of the difference in their biology, coupled with the similarity of many of their activities?

Charles Darwin laid a foundation for our 
comparison of species and classes of animals. Using the general theme of natural selection and differentiation of species derived from a common ancestor, Darwin points out that there are vestigial and rudimentary organs and systems common to many different taxa:

The homological construction of the whole frame [of the body] in the members of the same class is intelligible if we admit their descent fram a cormon progenitor, together with their subsequent adaptation to diversified conditions. - . With respect to development, we can clearly understand on the principle of variations supervening at a rather late embryonic period, and being inherited at a corresponding period, how it is that the embryos of wonderfully different forms should still retain more or less perfectly, the structure of the conmon progenitor. - - In onder to understand the existence of rudimentary organs, we have only to suppose that a progenitor possessed the parts in. question in a perfect state and that under changed habits of life they became greatly reduced either from simply disuse or through the natural selection of the individuals which were least encumbered by a superfluous part. [1]

Carl Sagan, a noted astrophysicist, was one of the designers of the capsules in the Voyager spacecraft mentioned above. In his book, The Dragons of Eden, Sagan has updated the abservations of Darwin with a discussion of the genetics of evolutionary development:

The book of life is very rich; a typical chromosomal DNA molecule in a human is composed of about five billion pairs of nucleotides. The genetic instructions of all other taxa [a biological division of species, classes, etc.. e.g., plant vs. animal] on earth are written in the same language, with the same code book. Indeed. this shared genetic language is one line of evidence that all the organisms on Earth are descended from a single ancestor, a single instance of the origin of life sane four billion years ago. (p. 23)
Sagan then makes an intriguing analogy. The genetic encoding that is carried through the DNA in chromosomes can be compared with all other forms of information and broken into component pieces. Since, as Sagan points out, there are four different nucleotides in each DNA molecule, and in a single human chromoscme there are five billion sets of nucleotides, we suddenly arrive at the fact that there are twenty billion bits of information in a single human chromosome. If this were to be compared with the binary bits of information in a cormputer, Sagan makes the astounding point that a single human chromosome carries the same information as a four thousand volume library, with each volume containing five hundred pages and each page three hundred words.

The genetic instructions of the DNA molecule, which are randomly mutated by environmental factors, allow for either successful or unsuccessful adaptation of the organism to its environment. But as organisms became more complex and as the physical environment became subject to quicker cycles of transformation and upheaval, as during ice ages, the chances for a successful, purely genetic transformation to meet the new conditions became more problematic. For these larger, more complex organisms, same new system of survival and adaptive information needed to be developed, and that, according to Sagan, was the extragenetic growth and specialization of the nervous system. Randam genetic transformation of the organism had reached its practical limits for success (for every success, thousands of failures would occur); henceforth, information relevant to survival and propagation, and the enhanced sensory systems to convey new information, would be processed in the brain.

The brain as we know it today, with its recognizable divisions, had already evolved same five hundred million years ago. It continued to grow and specialize as life forms changed from marine to amphibian to reptilian and, finally, to mammalian. At each of these stages, species have developed which have made optimun use of their brains within the taxa limits. The more intelligent of these animals have had larger brains to rum their bodies. The fact that there is excess brain capacity over and above that which is needed for simple biological maintenance is often seen as an indication of potential intelligence. In modern times, chimpanzees, dolphins, whales, and humans 
have the largest brain size to body mass ratios and are at the top of the mammalian intelligence scale.

One scientist who has worked on identifying the layered growth of animal brains over the course of evolution is Paul D. Maclean, head of the Laboratory for Brain Evolution and Behavior at the National Institute of Mental Health. Elaborating on the work of James Papez, Maclean has defined and explored three different parts of the brains of most animal species. In his work, as in most other scientific studies, the yardstick for measuring brain capabilities is usually the human brain. This has some obvious drawbacks as far as the question of animal consciousness is concerned, for, among other reasons, when they are experimentally manipulated, animals cannot "report" their sensations and feelings as a human can. Nevertheless, the underlying neurophysiology shows some interesting similarities between animals and humans.

Maclean has studied a number of species and found that there is an older brain which he calls the reptilian complex, because it was the major brain for reptiles going back to the age of the dinosaurs. The midbrain, also called the limbic system, surrounds the reptilian complex. Finally, the forebrain, or neocortex, developed its primacy after the other two and usually sits atop or surrounds them. Maclean emphasizes this in the follow ing dramatic way:

\section{Speaking allegorically, we might imagine that when a psychiatrist bids the patient lie on the couch, he is asking him to stretch out alongside a horse and a croco- dile.[2]}

Since the three divisions of the brain are found in all kinds of animals, from the most primitive to the most complex, we must take a more detailed look at their functions.

\section{The Reptilian Brain}

The reptilian brain, or hind brain, is the most basic part of the upper nervous system. it is often referred to as the brain stem, which feeds directly into the central nervous system at its lower end. It is here that the brain begins to process the input of the sensory systems of the body-touch, heat, cold, etc. It is here also that the directions imparted to the motor system (nerves that activate the heart, lungs, muscles, and other organs) proceed directly into the central nervous systen.

The "psychological" and behavioral states that characterize this part of the brain seen to involve ritualistic and hiecarchical displays, such as the spectra of dominance-submission, sexual courtship, display, mass migration, and ganging up on the weak. There is a certain "stolidness," to use sagan's term, about creatures, such as reptiles, that have this as the dominant part of their brain. Yet, the efficiency and necessity of this part of the brain in organisms is amply attested by the incredibly long period that reptiles have lived on Earth. No organism, least of all humans, with their elaborate, specialized brain, could exist, if it were not for the vital functions performed by this part of the brain.

\section{The Limbic System}

The limbic system of the brain, sometimes called the midbrain, is usually associated with older or less intelligent mammals, such as horses, marsupials, sloths, etc., because it is the chief feature of their brains. It, of course, exists in sane form in species from fish to humans. It is called the limbic system because it is associated with the functioning of the linbs of the body and the refinement of their uses.

It is a more powerful part of the brain, in the sense that a computer with more capacity and greater speed is considered more powerful. Psychologically, it appears to be the center of strong emotions, such as rage/fear, pleasure/pain, and rejoicing/sorrowing. The limbic system's ablity to affect our body with the release of strong endocrine chemicals is often reflected in our speech, as when we refer to our emotions with phrases like "love in our hearts" and "anguish in our guts," or when primitive societies locate a "demon" in the liver, bowels, etc. Same of the behaviors which are said to be controlled by this part of the brain are flight/fight, tension/relaxation, hunting, hoarding, aggression, bonding, searching, flocking, and rejoicing.

Carl Sagan has noted the following about the evolution of the limbic system: 
There are reasons to think that the beginnings of altruistic behavior are in the limbic system. Indeed, with rare exceptions (chiefly the social insects), manmals and birds are the only organisms to devote substantial attention to the care of their young--an evolutionary development that, through the long period of plasticity which it permits, takes advantage of the large information processing capability of the mamalian and primate brains. Iove seems to be the invention of the marmals.

Sagan immediately qualifies this statement to include non-mamals with lesser developed limbic systems:

This rule on the relative parental concern of marmals and reptiles is, however, by no means without exception. Nile crocodile mothers carefully put their fresh hatchlings in their mouths and carefully carry them to the comparative safety of the river waters; while sarengeti male lions will, upon newly dominating the pride, destroy all the resident cubs. [3]

To this I would add the poignant wait of the mother sea turtle, after journeying perhaps thousands of miles, at the edge of the surf for those of her hatchlings who can make it to the safety of the water on the day after they hatch. This scene probably stretches back tens of millions of years to the primordial age of the reptile. Still, there can be no doubt that the limbic system represents a great evolutionary advance toward the broadening of "mental" capability and behavior over the more primitive reptilian complex.

\section{The Neocortex}

The neocortex is the last and most revolutionary addition to the brain. With the neocortex, or forebrain, we move from the clearly delineated biological and behavioral functions of the reptilian and limbic systems to a more subtle and less well-defined set of functions and behaviors. Because human beings have by far the best developed neocortex, it is not surprising that the preponderance of our data on this part of the brain comes from studies made on human patients who have had some alteration or surgical stimulation of the cortical areas of the brain.

The subtlety of the functions of the neocortex argues not only for its importance to the conscious activity of the human being but also brings us to the precise heart of our difficulties in assessing the consciousness of animals. Although we can abserve a loss of hearing or sight in an animal, it is more difficult to see just what effects other manipulations in the cortical areas of animals would have on their functioning. They cannot report to us their sensations, or if they have tried to report their sensations, we have not learned the language of even one species other than our own. It reminds us of Bishop Berkeley's argument that if a tree falls in a forest and no one is there to hear it fall, does it really make a sound? This will have a bearing an our discussion of animal behavior below.

As we have already noted, the neocortex is the most recent evolutionary development of the neurological system in animals. It ranges from being a very small adjunct to the brain in fish and snakes to composing nearly half the brain in some marmals, while in its most advanced evolution in humans, it composes up to 708 of all neurons in the central nervous system.

structurally in humans, the neocortex has a number of interesting divisions, the most important being a left/right hemisphere split. The left hemisphere, once thought to be the dominant half of the brain, because, among other things, it controls right-handedness in humans, is apparently the side that controls linguistic and mathenatical ability. However, in most well-developed brains with an excess capacity beyond simple biological maintenance, there is considerable redundancy, with backup areas of the brain capable of picking up some functions lost when damage occurs to other parts of the brain. The right side of the neocortex is devoted to the aptitude for music, identification of visual patterns and the expression and recognition of emotions. These are thought to be emotions that are developed in the various limbic parts of the brain but are recognized and expressed by the necessary help of the right side of the neocortex.

Norman Geschwind, writing in Scientific American, notes that we know of mamologous areas that are found in all species that have 
a well-developed cerebral cortex."[4] Presumably, other species with less well-developed cortices could have other areas of their brains that are used for similar functions. Geschwind notes the results of experiments on rhesus monkeys who had occipital lobes experimentally manipulated, which had a direct effect on the monkeys' ability to reoognize faces. The monkeys were shown photographs of other monkeys and could readily identify them, but they lost this ability when areas of the occipital lobes were cut. This ability to reoognize individuals is a "valuable talent in a highly social animal and there has probably been strong selective pressure to improve its efficiency."[5] Another remarkable example of an animal's ability to select stimuli and recognize a specific feature is that of the tern, a sea bird. The mother leaves her chick in the bird colony of tens of thousands of birds to catch fish, and upon her return, she can recognize the exact squawk of her chick out of the deafening cacophony of thousands of chicks and adults in the colony.

Behaviorists and ethologists who share their views would argue that this is not an example of consciousness. It is, supposedly, a simple stimulus and response. But since they deny consciousness to humans as well, for the purposes of this paper, we can bracket this philosophical question and assert that what is significant is that animals as diverse as terns and rhesus monkeys exhibit qualities of attentiveness and behavior that closely resemble those of humans and in many instances may have more acute senses than we do. There can be no doubt that the human neocortex is not only larger in its mass to body weight ratio than other animals but is also more anatomically complex. still, there does not appear to be a clear-cut division between Homo sapiens and the rest of the animal kingdom (especially higher order animals) with regard to the capabilities of the nervous system. Rather, it is a question of the greater number of skills and responses as well as a question of their complexity and abstraction that seems to set animals apart from humans. It is the way that humans can, on a very subtle level, combine features of consciousness by creatively associating images and menories to form entirely new sets of thoughts that is missing in animals who must adapt to a narrower set of enviromental factors. After all, the human species, unlike any other animal, can adapt to habitats as diverse as the Ralihari desert and the ice flows of the Arctic.

\section{Artificial Intelligence}

Whether it is a measure of human solipsism or whether it is scme brave new form of Promethean endeavor, Homo sapiens is the only species to attempt to duplicate its own intelligence. We have, indeed, gone beyond mere storage and retrieval of our extrasomatic information (books, libraries, tapes, films, etc.) when we attempt to create our own thinking machines. The very recent and still forming convergence of modern philosophy of the mind, neurophysiology, and the science of cybernetics has focused the debate over intelligence on the search for artificial intelligence. If it is possible to reduce consciousness and intelligence to an electrical-mechanical set of programs and equations that would rival the working of the brain, we could do away forever with Cartesian dualism and simply work on a greater and greater aggregate of information processing. We could then move through the scale of phylo-intelligence until we arrived at the duplication of human intelligence. We could "reconcile symapses with souls." James Gleick asks, "Can machines be taught the most human of human traits-creativity, inspiration, imagination?"[6]

Gleick's article focuses on the work of Douglas Hofstadter, author of Godel, Escher, Bach, in his efforts to recreate the subtleties of the human thought process. The key ingredients, according to Hofstadter, are:

Perception. Menory. Analogy. Re-
grouping. - Abilities to do
very simple things, to take things
apart and put them back together
again in new ways, [are] so much at
the root of creativity. when a
composer like Bach conposed fugues,
you can practically see the wheels
churning. You can see Bach taking
things apart and putting then back
together-you can see that incredi-
ble fluidity." [7]

Hofstadter's work is controversial, because every cybernetic scientist would admit that an intuitive, surprising, and often irrational human being could hopelessly outflank even the most formidable computer, as depicted in Arthur C. Clarke's "2001--A Space Odyssey." It is a question of the perception, memory, 
analogy, and regrouping abilities of the brain that seemingly could never be duplicated; although, according to Gleick, there has been much progress made toward making the computer a more subtle instrument. Hofstadter does not use the typical problem-solving approach which asks the grand question and then works through processes until the minutiae are solved. Rather, Hofstadter starts with the minutiae, that aspect of the problem which has only the most peripheral connection with the larger problem he is solving, and by combining, associating, and regrouping the data, he attempts to arrive at a process that resenbles the workings of the human mind.

But it is also clear that animals share these same abilities of perception, memory, analogy, and regrouping. Bofstadter and his colleagues would do well to take a closer look at the abilities of animals before they tackle human intelligence. Gleick quotes Professor Marvin Minsky of M.I.T., who is both a supporter and a critic of Hofstadter's work:

\begin{abstract}
Nobody's ever tried to make a machine that could build a bird's nest. Instead they're all out there in the factories assenbling motors. People say, oh yes, the bird gets straws and sticks then in a nest and glues them in. But a motor is designed to be put together. The debris lying around on the forest floor isn't designed to be made into nests. [8]
\end{abstract}

Thus, the ability of a bird to take things that have connection to one another and remove and reassemble them into a structure that has coherence and function is something that no machine has been able to achieve. The processes are creative and subtle. The African lowland gorilla, likewise, will build a new nest in the trees everyday out of forest matter while on his foraging rounds in the jungle. And an otter will grab a rock off the sea floor to break open an abalone shell, so that he may conmence his feast.

\section{Animal Consciousness}

If there are similar, hanologous structures in evolutionary development and neurological functioning could we not postulate similarities in "mental states" based on explicable behavior patterns? Donald $R$. Griffin, in his book The question of Animal Awareness, provides us with an admittedly "unsophisticated but useful set of working definitions for states of awareness:"
Mental Awareness: every normal
person thinks about abjects and events that are remote in time and space from the inmediate flux of sensations.
Awareness: is the whole set of interrelated mental images of the flow of events; they may be close at hand in time and space like a toothache or remote as in an astro- nomer's concept of stellar evolu- tion.
An Intention: involves mental i- mages of events in which the in- tender pictures hinself as a parti- cipant and makes a choice as to which image he will bring to reali- ty. [9]

Combining these features, Griffin then formulates a working definition: "The presence of mental images and their use by an animal to regulate its behavior provide a pragmatic definition of consciousness." [10] Mental experiences involve not just the immediate flow of sensations to the brain's sensory complex but also their filtering through the lens of memory and association. As a result, mental images move from the passive realm to the active when an organism demonstrates intentionality. Intentionality here is seen in both its phenomenological sense-that of an arganism's consciousness apprehending the external world-and also in the sense that an organism "intends" actions that project into the future. To illustrate a rapid fire process of mental experiences and intentionality, we will take the example of a fox chasing a rabbit. The fox senses that the rabbit is real and is food. As it moves over the terrain, the fox must intend to act on its enviroment by leaping boulders, changing course, and, perhaps, by anticipating the movements of its prey. The raw sensory data (mental experiences) combine with mental images of measurement and motion and food, etc., to elicit choices for new movements which form a rapid and continuous stream of events.

In addition to demonstrating the process of intentionality, which is a fundamental characteristic of consciousness, one can also 
note the presence of other sensations in this scenario-hunger for the fox, fear for the rabbit, and, possibly, desperation for both of then. These animals, by their behavior, demonstrate sensations that we can abserve and measure (endocrine releases and other physiological events). And by the fact that humans experience honologous events and reactions, we can equate the animals' sensations to our own sensations of pain, fear, hunger, etc.

Communication is an important element of consciousiness. Two important forms of cornmanication are communication with the enviromment and conmunication between members of the same species. As an example of the former, Griffin cites the case of certain species of birds who apparently are able to use the magnetic alignment of the earth and star patterns to aid then in their migrations. He also discusses the activities of echolocating bats that use echoes to negotiate the conplex labyrinths of underground caves. Both of these examples suggest that these species must have a changing awareness of their environment and must redirect their behavior as new information becomes available. In the case of the echolocating bats, which Griffin nicknames "Andrea Doria bats," he cites data showing that the bats will memorize their environment and often pay only cursory attention as they fly through the caves. If new objects are put in the cave, the bats will often collide with them (hence "Andrea Doria," a ship that collided with another one despite the presence of radar). This demonstrates that they were flying by memory and did not expect the new objects.

As for the case of animals cammunicating with others of their own species or members of other species, Griffin cites the impressive work of Jane Goodall and the Gardners in teaching chimpanzees the rudiments of sign language and facial expressions. Most amazing of all is his discussion of the research of Karl von Frisch on honeybee dancing as a form of communication. Beginning in 1923 and extending for the next five decades, von Frisch studied the "waggle dances" of honeybees. He learned that bees retuming to the hive from their foraging afield do a type of dance to ommunicate to other bees vital information about food sources, their abundance, their direction and distance from the hive, and even information to the effect that they may have found a better place for the hive to locate in the event of a swarm. Bees may forage up to three miles from the hive, and the bee's sense of distance and direction as it forages is probably derived from the location of the sun, plus its sense of landmarks on its journeys. Other bees will dance and communicate information about their own journeys, and there will be a little comparison shopping before more bees are dispatched to the most promising food sources.

These and other examples of animal behavior are used by Griffin to refute the arguments of linguists, such as Noam Chonsky, and ethologists, such as Konrad Lorenz, that the difference between humans and animals can be seen in the former's use of language. Chamsky and others postulate sixteen design features of human communication that differ from those of animals. But upon closer examination, Griffin suggests, these are widely shared by animals, as well, or there is no clear evidence that they are actually unique to humans. These include vocal-auditory exchange, interchangeability (animals can be both transmitters and receivers), specialization (energy in the signal is small compared to the effect triggered by it), arbitrariness (how rigidly reproduced are the signals and their information content), discreteness (how discrete are the individual units of cormunication, i.e., words or syllables versus the single cycle of the honeybee waggle dance), etc.

In every case, the distinction between the supposedly unique characteristic of human commication and the animal communication blurs and becomes almost meaningless. Finally. Griffin quotes Alfred North Whitehead:

The distinction between man and animal is in one sense only a difference in degree. But the extent of the degree makes all the difference. The Rubicon has been crossed. [11]

That is, animals share all or most of the distinguishing characteristics of human Ianguage and communication which are the marks of consciousness. The main difference seems to be the quantitative degree and breadth of human language wich is what really distinguishes our species fram others. Yet there can be no doubt that the surn of these quantitative differences leaves a great gulf between humans and most other animal species. The intriguing exception to this rule may be dolphins and whales, who have brain size to 
body mass ratios comparable to our own. Dr. John Lilly has pioneered in the study of the intricate language patterns of many of these species, especially the bottle nose dolphins. He remains convinced that they are every bit as intelligent as humans, and considerably more benign, as well.

\section{Conclusion}

The work of behaviorists, linguists, and ethologists has failed to define any quality that humans possess that is not also possessed to some degree in other animals, especially the higher mammals. The subtle bias of these scientists has been to reduce the status of humans to the level of other animals which are seen as mere stimulus/response machines. But Donald Griffin argues, and the data can certainly support the idea, that we should, instead, see animals as beings that are much more kindred to ourselves. To paraphrase Whitehead, our abilities seen to be those of degree and not of kind. We have much more in common with animals than our previous chauvinistic history would reflect.

If this is true, then we have the responsibility and the duty to seek to understand and somehow commmicate with our neighbor species on this planet. The stewardship of life on this planet (the ability to regulate or destroy) has certainly devolved to us. And one need not look far to see that we have handled it poorly. Other species are declining and becoming extinct at an accelerating pace. Our treatment of other animals even when we study them borders on the criminally insensitive, as reflected in the growing scandal of the mistreatment of laboratory animals.

Charles Darwin, the great modern scientist who first broke ground in explaining our connection with other animals, painted a very poignant picture of our insensitivity. He describes the sentience and loyalty of a dog whose master was a biologist performing vivisection on it:

[The dog] licked the hand of the operator [until it fell unconscious]; this man, unless the operation was fully justified by the increase of our knowledge, or unless he had a heart of stone, must have felt remorse to the last hour of his life.[12] one can only womder if, upon the arxival of Sagan's sought after extraterrestrials, whether we as humans would be so overlooked and disregarded. Would they be as insensitive? Can we learn this lesson now?

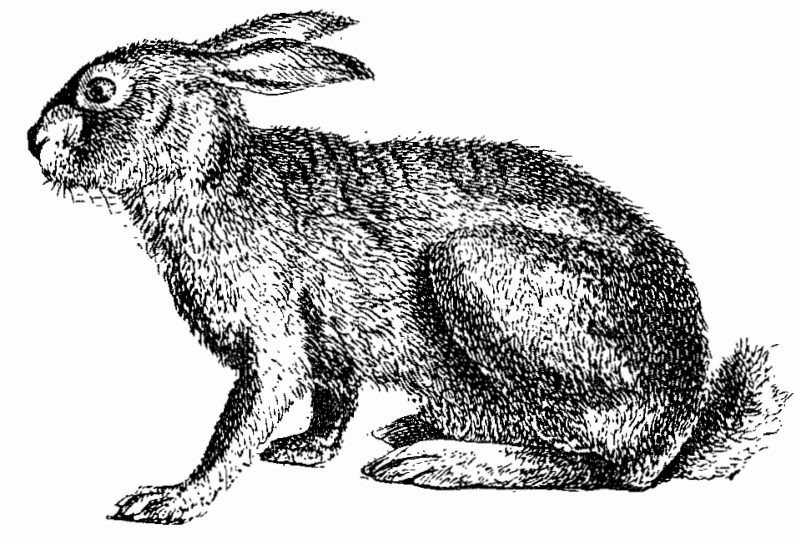

NOTES

1. Charles Darwin, The Descent of Man (New York: Heritage Press, 1972), pp. $\frac{17-18 .}{18}$

2. Charles Hampden-Turner, Maps of the Mind (New York: Macmillan Publishing Co., $\overline{1981)}$, p. 80.

3. Ibid., pp. 64-5.

4. Norman Geschwind, "Specializations of the Human Brain," Scientific American (September, 1979), p. 180.

5. Ibid.

6. James Gleick, "Exploring the Iabyrinth of the Mind," New York Times Magazine (August 21, 1983), pp. 199, 24.

7. Ibid., p. 24; also, Hampden-Turner, op. cit.., p. 100 .

8. Ibid.. p. 26 .

9. Donald R. Griffin, The question of Animal Awareness (New York: Rockefeller University Press, 1976), p. 5.

10. Ibid.. p. 7.

11. Ibid. 37.

12. Darwin, op. cit.. p. 59. 